\title{
Cerebral blood flow in systemic lupus erythematosus with and without central nervous system involvement
}

\author{
HASSANE H AWADA,* HUBERT L MAMO,$\dagger$ ALBERT G LUFT, $\dagger$ JEAN C PONSIN, $\dagger$ \\ MARCEL F KAHN*
}

From the * Département de Rhumatologie Hôpital Bichat; and †Département d'Explorations Fonctionnelles du Système Nerveux Hôpital Lariboisière, and Groupe de Recherches de Physiologie et de Physiopathologie Cérébrovasculaire, Faculté de Médecine Lariboisière-Saint-Louis, Université Paris VII, Paris, France

SUMMARY Regional cerebral blood flow (rCBF) was studied by the intravenous 133Xe method in 38 patients with systemic lupus erythematosus (SLE); 21 patients had neuropsychiatric manifestations $\left(\mathrm{N}^{+}\right)$and 17 did not $\left(\mathrm{N}^{-}\right)$. Twelve of the $\mathrm{N}^{+}$patients had had neuropsychiatric episodes less than one year before measurement of CBF ("recent" $\mathbf{N}^{+}$), while seven patients in this group had had episodes over a year before measurement ("old" $\mathrm{N}^{+}$). The results were compared with those obtained from a group of 27 age-matched normal healthy subjects. It was found that, in most of the $\mathrm{N}^{+}$and $\mathrm{N}^{-}$patients, rCBF was evenly distributed bilaterally, but there was a "patchwork" of high/normal and low flow areas. This disturbance of rCBF distribution was significantly greater in "recent" $\mathrm{N}^{+}$patients than in "old" $\mathrm{N}^{-}$patients, but was not a function of the potential evolution of systemic lupus erythematosus. It was also found that there was a reduction in the physiological high frontal rCBF in the "old" $\mathrm{N}^{+}$patients. No correlation could be found between $\mathrm{rCBF}$, the topography of the neuropsychological lesions, other neurological investigations or the glucocorticoid dosage and treatment schedules.

Cerebral complications constitute the second most serious risk factor, after renal complications, in patients suffering from systemic lupus erythematosus. ${ }^{1}$ However, their reported frequency varies widely, ranging from 24 to $75 \% .^{2}$ This variability is probably due in part to the difficulty encountered in demonstrating the organic nature of certain psychical symptoms, and to a lesser extent to the fact that the corticotherapy administered to these patients may itself cause cerebral disorders. The clinical expression of these complications is multiform and may consist of disturbances of behaviour or mood, headaches (often migraine-like), signs of cerebral excitation (such as epilepsy) or deficiency (such as hemiplegia), cerebellar or brainstem deficit, or dyskinesia of various types. In many of these nervous disorders lesions of the microcirculation, usually unspecific, seem to be

Address for reprint requests: $\operatorname{Pr} \mathrm{H}$ Mamo, Laboratoire de Physiologie et Physiopathologie Cérébrovasculaire Faculté de Médecine Lariboisière-Saint-Louis 10, avenue de Verdun, 75010, Paris, France.

Received 10 February 1987 and in revised form 27 May 1987. Accepted 1 June 1987. most responsible. A few studies have been published in which cerebral blood flow (CBF) was measured in patients with systemic lupus erythematosus. These studies used ${ }^{15} \mathrm{O}$ brain scanning ${ }^{34}$ or positron emission tomography (PET). ${ }^{5}$ The aim of the present investigation was to study the cerebral circulation of systemic lupus erythematosus patients by measuring regional CBF (rCBF) from clearance of intravenously injected ${ }^{133} \mathrm{Xe}$, and to compare our results with those obtained by means of PET and ${ }^{15} \mathrm{O}$ scan.

\section{Methods and patients}

\section{(a) Patients}

Thirty eight patients, comprising 37 women and a man, were examined. Mean age was 32, 4 SD 10 years (range 17-58): Systemic lupus erythematosus was diagnosed on the basis of the 1982 revised criteria defined by the ARA $1982 .^{6}$ Thirty two patients fulfilled more than four criteria, the remaining six fulfilled three criteria. All patients had positive assays for antinuclear antibodies and anti-native DNA antibodies (radioimmunoassay). Twenty one patients had or had had neurological or psychiatric disorders (group $\mathrm{N}^{+}$). The neurological signs are detailed in table 1 . In this group, 12 subjects were tested less than 1 year after any neurological 
Table 1 Neuropsychiatric manifestations in patients of group $\mathrm{N}^{+}$

\begin{tabular}{lll}
\hline Type & $n=21$ & $\%$ of cases \\
\hline Seizures & 8 & $38 \cdot 1$ \\
$\quad$ "grand mal" & 4 & \\
temporal & 2 & \\
$\quad$ focal & 1 & \\
"petit mal" & 1 & \\
Psychiatric episodes & 6 & 28.6 \\
$\quad$ organic & 2 & \\
functional & 4 & $33 \cdot 3$ \\
Focal hemispheric deficit & 7 & $14 \cdot 7$ \\
Headache & 3 & $14 \cdot 7$ \\
Vertigo & 3 & $9 \cdot 5$ \\
Meningitis & 2 & $9 \cdot 5$ \\
Encephalitis & 2 & \\
\hline
\end{tabular}

episode (mean 3,75 SD $4 \cdot 3$ months) and nine subjects after a longer delay (mean 57,3 SD 45 months). The remaining 17 had never shown any clinically detectable neurological disorder (group $\mathrm{N}^{-}$). Groups $\mathrm{N}^{+}$and $\mathrm{N}^{-}$were statistically comparable in age, sex, number of systemic lupus erythematosus criteria, duration of the disease, associated disorders, biological examinations and the existence of renal lesions (there were three mesanglial glomerulonephritis in each group, five proliferative glomerulonephritis in group $\mathrm{N}^{+}$and one in group $\mathrm{N}^{-}$). The only significant difference between them concerned the development of the disease: 10 patients had active disease and 11 had inactive or low activity disease in group $\mathrm{N}^{+}$; there were 14 "active" and three "inactive" cases in group $\mathrm{N}^{-}\left(\mathrm{p}<0.05 \chi^{2}\right.$ test). Disease activity was clinically and biologically evaluated when the study was carried out. The disease was considered to be active if the clinical onset or an exacerbation of any systemic lupus erythematosus manifestation were observed, either alone or associated with one or more of the following biological manifestations: an increase in ESR, the presence of leucopenia or thrombocytopenia, an increase in anti-DNA titre or a decrease in total haemolytic complement or $\mathrm{C}_{3} \mathrm{C}_{4}$ levels. The disease was considered to be inactive if no new clinical manifestation occurred or if the clinical status was stable for more than 3 months despite corticosteroid treatment being decreased or unchanged.

\section{(b) Control group}

The results obtained in systemic lupus erythematosus patients were compared with those obtained by the same method on a control group of normal subjects. Twenty seven healthy normal volunteers, eight females and 19 males, aged $30 \pm 9$ years, gave their consent to CBF measurement. Although the systemic lupus erythematosus patients were almost exclusively females, the composition of the control group was not changed because the female and male subgroups had comparable ages (28 SD 9 and 31 SD 7, respectively), mean CBFs (60 SD 5 and 61,5 SD 4.5), hyperfrontality indices (8 SD 5.5 and 7.4 SD 7) and heterogeneity indices (63 SD 14 and 64 SD 16).

(c) $\mathrm{rCBF}$ measurements

The non-invasive method of rCBF measurement used and the computation of the various parameters have been described in detail in previous publications ${ }^{7-11}$; only the essential points will be given here. The tracer, ${ }^{133}$ Xenon, was administered intravenously and tracer clearance curves were obtained by recording the activity received by 26 head detectors, which were equally spaced over each hemisphere (fig). The doses of radio-isotope injected (15-20 mCi) were such as to ensure satisfactory counting statistics $(800-1000$ cps at the peak of the clearance curves) with a sampling time of $6 \mathrm{~s}$ so that the statistical fluctuations were much smaller than the physiologically induced fluctuations during repeated measurements. The analysis of the clearance curves was performed using a two-compartment model ${ }^{12}$ in which the first, fast flow, compartment represents grey matter (fig) and the second parallel, slower flow, compartment represents both white matter and contaminated extracerebral tissues (bone, scalp, meninges). The input function of the model, that is the variation with time of the tracer concentration in the arterial blood arriving in the brain, was estimated by measuring the end tidal tracer concentration. ${ }^{13} 14$ Blood flow per unit mass of grey matter was calculated using a least squares method ${ }^{9}$ from the clearance curves and the arterial concentration curve. The grey matter flow measurements were similar to the results obtained by intracarotid injections of the $\operatorname{tracer}^{8}$ (coefficient of variation = SD $10 \%$ ). The standard deviation of repeated measurements in the same patients was about $9 \mathrm{ml} / 100 \mathrm{~g} / \mathrm{min}$ for the hemisphere mean flow and $11 \mathrm{ml} / 100 \mathrm{~g} / \mathrm{min}$ for the regional flow values. These values are similar to those obtained by Blauenstein $e t \mathrm{al}^{15}$ by the inhalation method.

The patient undergoing CBF measurement was placed in a specially allocated room separated from the data treatment area so that the recordings took place under the best possible conditions. A saline perfusion was set up in the brachial vein and the head detectors positioned over both hemispheres in a symmetrical manner, perpendicularly to the skull. End tidal $\mathrm{CO}_{2}$ concentrations (from which the alveolar $\mathrm{PCO}_{2}$ and arterial $\mathrm{PCO}_{2}$ could be calculated) were measured during the examination, using a capnograph. Arterial blood pressure was measured immediately before and after CBF measurement.

\section{(d) Other neurological investigations}

Six patients had previously been examined by CT scan and 14 had been given an EEG.

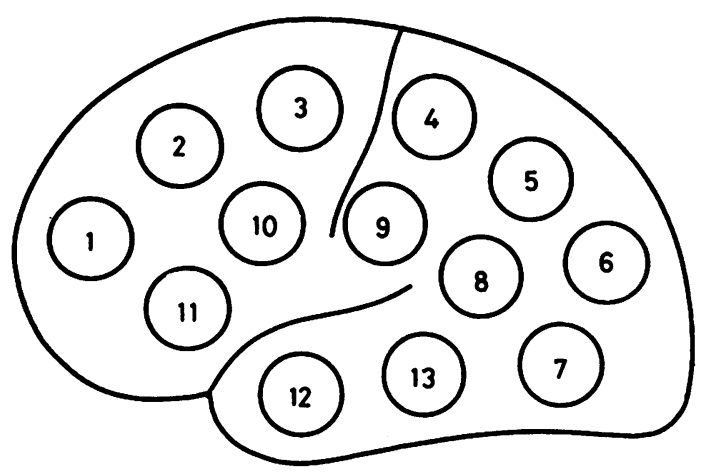

Fig Topography of probes. 
(e) Statistical methods

The following statistical analyses were performed. (a) Calculation of the index of hyperfrontality defined as $(F A-F P) / F H \times 100$, where FA is the mean flow in the frontal area (probes 1, 2, 3, 10, 11 (fig)); FP the mean flow in the parietal, temporal and occipital areas (probes 4, 5, 6, 7, 8, 9, $12,13)$ and FH the mean flow in the entire hemisphere; $(b)$ heterogeneity of regional flow was quantified by an index of heterogeneity defined in each subject, by $\frac{\delta \mathrm{n}-1}{\mathrm{~m}} \times 1000$, where $\delta \mathrm{n}-1$ is the standard deviation of CBF estimated by the 13 regional probes and $m$ the mean CBF; $(c) \chi^{2}$ test was used for qualitative comparisons between different groups; (d) differences were tested for significance by Student's $t$ test; (e) correlation coefficients were calculated according to conventional methods; $(f)$ the Fisher test was used for comparisons of more than two means (variance analysis).

\section{Results}

\section{Mean $C B F$ and systemic lupus erythematosus}

(table 2)

No significant difference was observed between the mean CBF of the two hemispheres of the patient group (60.5 $\pm 10 \cdot 7)$ and that of the controls $(61 \pm$ $4 \cdot 5)$. The occurrence of neuropsychiatric episodes in the systemic lupus erythematosus patients did not effect the overall level of CBF $(59 \pm 11 \cdot 5)$, and there was no evidence of interhemisphere asymmetry in the CBF of the patients (left hemisphere 60.5 \pm 10.7; right hemisphere $59 \cdot 5 \pm 10$ ).

All these CBF measurements were recorded after the $\mathrm{PaCO}_{2}$ had stabilised at a normal level (38.68 in control group, 38.80 in systemic lupus erythematosus group). No significant changes in arterial pressure were found before or immediately after CBF determination.

\section{Regional distribution of $C B F$ and systemic lupus erythematosus}

The distribution of $\mathrm{rCBF}$ was heterogeneous in most (24) of the patients examined, producing a "patchwork" effect with areas of normal or increased blood flow adjacent to regions of reduced flow. This is reflected in the rCBF heterogeneity index, defined in Methods and patients. It was greater in the patient group $(88 \pm 35)$ than in the controls $(64 \pm 15)$ with the difference being significant $(p<0.01)$. This index was analysed in terms of the presence or absence of neuropsychiatric episodes $\left(\mathrm{N}^{+} / \mathrm{N}^{-}\right)$, the interval between these episodes and rCBF measurement and activity of systemic lupus erythematosus. The two sub-groups of $\mathrm{N}^{+}$patients, "recent" $\mathrm{N}^{+}$, comprising patients who had had episodes less than a year prior to CBF measurement, and "old" $\mathrm{N}^{+}$, comprising patients in whom the interval between the last episode and CBF measurement was greater than 1 year, were analysed separately. It was found that: $(a)$ the index was significantly higher in "recent" $\mathrm{N}^{+}$patients (101 SD 43) than in "old" $\mathrm{N}^{+}$(74 SD 37) and $\mathrm{N}^{-}$(85 SD 23) patients, (b) the index was not correlated with either the activity of systemic lupus erythematosus or with the presence or absence of renal damage (table 3).

\section{Hyperfrontality index of $C B F$ (table 2)}

It is well established that the hyperfrontality pattern of $\mathrm{CBF}$ is a characteristic of the resting state when measured by the ${ }^{133} \mathrm{Xe}$ technique with a multidetector system. ${ }^{716-20}$ No significant difference in hyperfrontality was found between the patients (5.4 SD 5.2) and the normal control subjects (7.6 SD 6.4). However, CBF hyperfrontality appeared to be lower in the "old" $\mathrm{N}^{+}$patients (2.06 SD 3.4) than in the "recent" $\mathrm{N}^{+}$patients $(7 \cdot 16 \pm 5 \cdot 15)(t=2 \cdot 53, \mathrm{p}<0.05)$.

\section{$4 \quad C B F$ and other neurological investigations}

There was no significant correlation between the alterations in the EEG of group $\mathrm{N}^{+}$patients (14 cases) and the index of rCBF heterogeneity. Similarly, there was no correlation between the CT scan and rCBF; in five cases whose CT scans were normal the rCBF distributions were heterogeneous.

\section{$5 \quad C B F$ and treatments}

All patients investigated were treated with corti-

Table 2 Results in systemic lupus erythematosus patients and in controls. Patients have been divided into two groups according to the presence (group $\mathrm{N}^{+}$) or the absence (group $\mathrm{N}^{-}$) of neuropsychiatric manifestations in disease history. Group $N^{+}$has been subdivided in two subgroups according to the interval between the last neuropsychiatric manifestation and CBF measurement, "recent" for a period of less than one year and "old" for a period of more than one year

\begin{tabular}{|c|c|c|c|c|c|c|}
\hline \multirow[b]{3}{*}{$\begin{array}{l}\text { Mean CBF }(\mathrm{ml} / 100 \mathrm{~g} / \mathrm{min}) \\
\text { Heterogeneity index } \\
\text { Hyperfrontality index }\end{array}$} & \multirow{3}{*}{$\begin{array}{l}\begin{array}{l}\text { Patients } \\
(n=38)\end{array} \\
60.5 \pm 10 \cdot 7 \\
88 \pm 35 \\
5.4 \pm 5.2\end{array}$} & \multicolumn{2}{|l|}{ Group $N^{+}$} & \multirow[b]{2}{*}{$\begin{array}{l}\text { Group } N^{-} \\
(n=17)\end{array}$} & \multirow[b]{2}{*}{$\begin{array}{l}\text { Controls } \\
(n=27)\end{array}$} & \multirow[b]{2}{*}{$\begin{array}{l}\text { Fisher } \\
\text { test }\end{array}$} \\
\hline & & $\begin{array}{l}\text { Recent } \\
(n=12)\end{array}$ & $\begin{array}{l}\text { Old } \\
(n=9)\end{array}$ & & & \\
\hline & & $\begin{array}{cl}61 & \pm 13 \\
101 & \pm 43^{*} \\
7 \cdot 16 \pm 5 \cdot 75\end{array}$ & $\begin{array}{l}56 \pm 9 \\
74 \pm 37 \\
2.06 \pm 3.4\end{array}$ & $\begin{array}{l}62 \cdot 5 \pm 9 \cdot 5 \\
85 \pm 23 \\
5.9 \pm 5 \cdot 1\end{array}$ & $\begin{array}{l}61 \pm 4.5 \\
64 \pm 15 \\
7.6 \pm 6.4\end{array}$ & $\begin{array}{l}\text { NS } \\
\mathrm{p}<0.01 \\
\mathrm{NS}\end{array}$ \\
\hline
\end{tabular}

* Refers to the significantly highest group index. 
Table 3 Results in systemic lupus erythematosus patients according to the activity of the disease

\begin{tabular}{|c|c|c|c|}
\hline & $\begin{array}{l}\text { Active disease } \\
(n=24)\end{array}$ & $\begin{array}{l}\text { Inactive disease } \\
(n=14)\end{array}$ & $\begin{array}{l}\text { Student } \\
\text { t test }\end{array}$ \\
\hline $\begin{array}{l}\text { Mean CBF } \\
\text { Heterogeneity index } \\
\text { Hyperfrontality index }\end{array}$ & $\begin{array}{l}61 \pm 10 \\
91 \pm 33 \\
6 \cdot 2 \pm 6\end{array}$ & $\begin{array}{l}59 \pm 11 \\
83 \pm 38 \\
4 \pm 3.7\end{array}$ & $\begin{array}{l}\text { NS } \\
\text { NS } \\
\text { NS }\end{array}$ \\
\hline
\end{tabular}

costeroids. No significant correlation was found between the duration of treatment or the doses given and $\mathrm{rCBF}$ results.

\section{Discussion}

The results of this study demonstrate that the $\mathrm{rCBF}$ is frequently heterogeneous in its distribution ("patchwork" pattern). This perturbation of the cerebral blood flow appears to be relatively independent of neuropsychiatric episodes since it was observed in both $\mathrm{N}^{+}$and $\mathrm{N}^{-}$patient groups. Pinching $e t$ al ${ }^{3}$ have observed similar results in a study of CBF and cerebral metabolism using ${ }^{15} \mathrm{O}$ PET. rCBF heterogeneity might reflect diffuse vascular disturbance in systemic lupus erythematosus, regardless of their clinical expression. Bresniham et al $l^{4}$ studied CBF with ${ }^{15} \mathrm{O}$ brain scanning and noted diffuse abnormalities of the cerebral circulation during the course of the illness, but they did not study patients with no neuropsychiatric manifestations. This disturbance of the flow distribution in systemic lupus erythematosus is also in accordance with anatomical lesions reported. ${ }^{2122}$ In most cases the lesions are nonspecific (intimal thickening in the arterioles, various types and degrees of haemorrhage, microinfarctions and, less frequently, necrotising angeitis). There was no major correlation between the topography of the vascular lesions, and the neuropsychiatric signs. ${ }^{21} 22$ This lack of correlation between rCBF and neuropsychiatric manifestations is, however, not total. When the $\mathrm{N}^{+}$patients were ranked according to the length of time between rCBF and the neuropsychiatric episodes, it was found that rCBF heterogeneity was greater in patients with the shortest interval between measurement and episodes. This may indicate that, if the cerebral vascular effect of systemic lupus erythematosus is the same in both $\mathrm{N}^{+}$ and $\mathrm{N}^{-}$groups, and if there is no topographical correlation between rCBF and the neurological signs, then the episodes must leave a non-specific "imprint" on the rCBF distribution which tends to decrease with time.

The second positive results from this study is the demonstration of the reduction in the CBF physiological hyperfrontality in the "old" $\mathrm{N}^{+}$patients compared to that of the control group. The meaning of this change is unclear. Although psychic manifestations are frequent in systemic lupus erythematosus, no correlation could be found between their presence and changes in frontal lobe rCBF. There is no evident reason why this reduction in hyperfrontality should be observed only in those systemic lupus erythematosus patients who had neurological or psychic episodes some time prior to CBF measurement ("old" $\mathrm{N}^{+}$). Perhaps an explanation may be found by comparison with other causes of reduction or loss of hyperfrontality, as the vascular factor is dominant in systemic lupus erythematosus. There are marked dissimilarities between the results of Melamed $e a^{23}$ and ourselves ${ }^{7}$ on the evolution of hyperfrontality with age and the vascular background of the subject. We found that individuals with diffuse vascular disease or with vascular risk factors almost always show a reduction or loss of hyperfrontality between the fifth and sixth decade, whereas hyperfrontality persists in normal individuals of the same age. Our observations on patients with systemic lupus erythematosus and "old" neuropsychiatric manifestations are similar, despite the patient population being younger. The characteristic common to these two groups of subjects is the presence of vascular damage, atheroma in the patients examined in the hyperfrontality and age study, and vascularitis in the systemic lupus erythematosus patients. The fact that this drop in cerebral blood flow significantly involves the frontal regions may be because neuronal metabolism is greater in areas involved in elaborated functions, and thus these regions are more sensitive to vascular lesions. The time delay between the reduction in hyperfrontality and the neuropsychiatric signs suggests a differential slowing effect of the arteriolar lesions on the neuronal metabolism of the frontal region.

Finally, this study of rCBF in systemic lupus erythematosus provides data which could form a starting point for the development of a clearer understanding of the pathophysiology of this systemic disease.

The authors thank Professor JP Mery and Professor J Frottier on whose patients this study was carried out. They also thank A Segelman, Ch Ait Bachir and J Briant for their invaluable technical help.

\section{References}

1 Dubois F. Systemic Lupus Erythematosus. 2nd ed. Los Angeles: Univ South Carol Press 1974:305-26.

2 Meyer O, Margulis J, Kahn MF. Lupus érythemateux disséminé. In: Kahn MF, A Peltier, eds. Maladies dites systémiques. Paris: Flammarion, 1982:204-6.

3 Pinching AS, Travers RL, Hughes GRV, Jones T, Moss S. $\mathrm{O}^{15}$ brain scanning for detection of cerebral involvement in systemic lupus erythematosus. Lancet 1978;1:898-900.

4 Bresniham B, Hohmeister R, Cutting J, et al. The neu- 
ropsychiatric disorders in SLE: evidence for both vascular and immune mechanisms. Ann Rheum Dis 1979;38:301-6.

5 Hiraiwa M, Nonaka C, Abe T, Lio M. Positron emission in systemic lupus erythematosus: relation of cerebral vasculitis to PET findings. AJNR 1983;4:541-3.

6 Tan EM, Cohen AS, Fries JF, Masai AT, McShane DJ, Rothfield NF, Schaller JG, Talal N, Winchester RJ. The 1982 revised criteria for the classification of SLE. Arthritis Rheum 1982;25:1271-7.

7 Mamo H, Meric P, Luft A, Seylaz J. Hyperfrontal pattern of the cerebral blood flow in man. Arch Neurol 1983;40:626-32.

8 Meric P, Seylaz J, Correze JL, Luft A, Mamo H. Measurement of regional blood flow by intravenous injections of 133 Xenon. Acta Neurol Scand 1977;56(suppl 64):462-3.

9 Meric P, Seylaz J; Correze JL, Luft A. Measurement of regional blood flow by intravenous injection of 133 Xenon. Med Progress Technol 1979;6:53-63.

10 Meric P, Luft A, Seylaz J, Mamo H. Analysis of reproducibility and sensitivity of atraumatic measurement of regional blood flow in cerebrovascular diseases. Stroke 1983;14(suppl 1):82-7.

11 Seylaz J, Meric P, Correze JL, Luft A, Mamo H. Analytical problems associated with the non invasive measurement of cerebral blood flow in cerebrovascular diseases. Med Biol Eng Comput 1980;18:39-47.

12 Obrist WD, Silver D, Wilkinson WE, Harel D, Heyman A, Wang WS. The $133 \mathrm{Xe}$ inhalation method: assessment of rCBF in carotid endarteriectomy. In: Langfitt TW, McHenry LC, Reivich M Jr, Wollman $\mathrm{H}$, eds. Cerebral Circulation and Metabolism. New York: Springer-Verlag 1975:239-46.

13 Obrist WD, Thompson HK, King CH, Wang HS. Determination of regional cerebral blood flow by inhalation of $133 \mathrm{Xe}$. Circ Research 1967;20:124-34.

14 Wilson EM, Wills EL, Risberg J, Halsey JH, Gerard JD, May
CP. Measurement of regional cerebral blood flow by the 133 $\mathrm{Xe}$ inhalation method with an on-line computer. Comput Biol Med 1977;7:143-57.

15 Blauenstein UW, Hasley JH, Wilson EM, Wills ED, Risberg J. $133 \mathrm{Xe}$ inhalation method analysis of reproducibility: some of its physiological implications. Stroke 1979;8:92-102.

16 Wilkinson IMA, Bull JWD, Du Boulay GM, Marshall J, RossRussel RW, Symon L. Regional blood flow in the normal cerebral hemisphere. J Neurol Neurosurg Psychiatry 1969;32:367-78.

17 Sveindottir E, Torlog P, Risberg J, Lassen NA. Circulation of regional cerebral blood flow: Initial-slope-index compared to height over total area values. In: Ross-Russel RW, ed. Brain and Blood Flow. London: Pitman Medical, 1971.

18 Philipson L, Wottrich G. Svensk Färgbildsskärm visar bloodflöde. Mediecinsk Teknik 1977:1

19 Lassen NA, Roland PE, Larsen E, Melamed E, Soh K. Mapping of human cerebral functions: A study of the regional cerebral blood flow pattern during rest, its reproductibility and activation seen during basic sensory and motor functions. Acta Neurol Scand 1977;(suppl 64):262-3.

20 Ingvar DH. Hyperfrontal distribution of the cerebral grey matter flow in resting wakefulness; on the functional anatomy of the conscious state. Acta Neurol Scand 1979;60:12-25.

21 Johnson RT, Richardson EP. The neurological manifestations of SLE. A clinical pathological study of 13 cases and review of literature. Medicine 1968;47:337-69.

22 Ellis SG, Verity MA. CNS involvement in SLE: a review of neuropathologic findings in 57 cases 1955-1957. Semin Arth Rheum 8: 1979:212-21.

23 Melamed E, Lavy S, Benton S, Cooper G, Rinot Y. Reduction in regional blood flow during normal aging in man. Stroke 1980;1:31-4. 